\title{
Green Tea and its Effect on Hemostasis Measured by Thrombelastography
}

\author{
Bryant Alyzandyr Eumhyn Chua, ${ }^{1}$ Trully D. Sitorus, ${ }^{2}$ Nadjwa Zamalek Dalimoenthe ${ }^{3}$ \\ ${ }^{1}$ Faculty of Medicine Universitas Padjadjaran, ${ }^{2}$ Department of Pharmacology and Therapy \\ Faculty of Medicine Universitas Padjadjaran, ${ }^{3}$ Department of Clinical Pathology Faculty of \\ Medicine Universitas Padjadjaran/Dr. Hasan Sadikin General Hospital Bandung
}

\begin{abstract}
Background: Increasing health problems may come from changes in lifestyle including stressful lifestyles, high calorie diets, and lack of physical activity. Those may also lead to an increase occurrence of abnormal hemostasis. Green tea has been well known for its many benefits, including its antithrombotic effect. The aim of this study was to determine whether the consumption of green tea actually affects hemostasis and to measure changes in hemostatic parameters after its consumption.
\end{abstract}

Methods: A preliminary explorative study was conducted on 3 healthy female subjects aged between 21 to 22 years old for 8 weeks from October to November 2012 in Jatinangor, Sumedang, Indonesia. The subjects were subjected to initial thrombelastography analysis and started drinking green tea twice a day after meals. The solution was made by steeping a teabag in $250 \mathrm{ml}$ water of $70^{\circ} \mathrm{C}$ for 2 minutes. After 8 weeks, another thrombelastography analysis was performed to the subjects.

Results: Pre- and post-intervention results of the analysis were averaged and compared according to the parameters. The results of this study showed prolonged $\mathrm{R}$ (Reaction-time) and $\mathrm{K}$ (K-time), decreased $\alpha$ (angle) and MA (Maximum Amplitude), and increased LY30 (lysis at 30 minutes), showing an overall reduction in coagulability.

Conclusions: The consumption of green tea twice a day for 8 weeks affects hemostasis with hemostatic parameters measured by thrombelastography show differences before and after consumption.

Keywords: Green tea, hemostasis, thrombelastography

Correspondence: Bryant Alyzandyr Eumhyn Chua, Faculty of Medicine, Universitas Padjadjaran, Jalan Raya BandungSumedang Km.21, Jatinangor, Sumedang, Indonesia, Phone: +628170205778, Email: alyzandyr@gmail.com 